\title{
Quid sit bene dictum
}

\author{
What it is to be well said
}

Pedro Paulo da Costa Coroa

https://orcid.org/0000-0002-9854-7914 - E-mail: pcoroa@ufpa.br

\section{RESUMO}

O nosso objetivo com este artigo é mostrar que a relação entre filosofia e crítica literária, em Benedito Nunes, mais que uma vocação pessoal, é o pendor natural às boas práticas, tanto filosóficas quanto as literárias, em sentido amplo. Estamos falando de uma congeneridade originária, como afirma o próprio Benedito Nunes. E essa perspectiva se consolida no pensamento moderno graças a Kant e suas críticas, sobretudo sua Kritik der Urteilskfraft, obra que altera os rumos da história da filosofia ao deslocar seu centro da ciência para a estética.

Palavras-chave: Filosofia. Literatura. Estética. Crítica.

\begin{abstract}
Our objective with this article is to show that the relationship between philosophy and literary criticism, in Benedito Nunes, more than a personal vocation, is the natural tendency to good practices, both philosophical and literary, in a broad sense. And this perspective is consolidated in modern thought thanks to Kant and his criticisms, especially his Kritik der Urteilskraft, work that changes the course of the history of philosophy by shifting its center from science to aesthetics.
\end{abstract}

Keywords: Philosophy. Literature. Aesthetics. Criticism. 


\section{Benedito Nunes e a koinophilia entre Filosofia e Poesia}

Escrever sobre o "Professor" Benedito Nunes exige de nós, que tão de perto o conhecemos, paradoxalmente, uma atitude impessoal e objetiva. Mas, talvez, esta seja a única forma de mostrar o respeito que ele, invariavelmente, sempre fez por merecer. Jamais valerá a pena emitir uma mera opinião sobre ele - sobre sua vida e profissão - que expresse, apenas - por mais importante que isso possa ser para cada um de nós, individualmente -, a amizade e o sentimento que cultivamos por ele durante muitos anos. Por isso mesmo, discorrer acerca da atividade intelectual de Benedito Nunes só vale à pena se isso quer dizer falar sobre o que a ele sempre interessava - e despertava nele o desejo de vínculo. A palavra "interesse", aliás, vem do latim inter-esse, "estar entre". E aquilo "entre que" o Professor Benedito sempre se sentiu à vontade, por ter se tornado o seu lócus próprio - portanto, seu "lugar natural" -, o sítio que define, precisamente, o seu modo de ser-entre, seu inter-esse, é, na verdade, um interregnum, ou seja, uma fronteira - sem frente e sem fundos - entre dois domínios: o da filosofia e o da poesia. $\mathrm{E}$ nessa linha imaginária que as separa, ele soube, como poucos, pousar seu pensamento - e mantê-lo em equilíbrio.

Em 2005, em um texto escrito sob a forma de memorial para o III Ciclo de Conferências "Caminhos do Crítico", promovido pela Academia Brasileira de Letras, e com o título "Meu caminho na crítica", o eixo temático em torno do qual Benedito Nunes constrói seu depoimento é, como sempre, a relação e a imbricação existentes entre suas pesquisas filosóficas e suas análises como crítico literário. Mas, já na apresentação, somos convidados a lembrar que: “... desde Kant a filosofia também foi chamada de crítica" (NUNES, 2005, p. 289).

Embora o contexto específico ao tipo de academia a que deveria ser ambientada sua exposição parecesse exigir um maior acento e ênfase na abordagem que nós, tradicionalmente, tomamos como literária, o memorialista - por exemplo, na comparação entre a Ética, de Espinosa, e a Divina Comédia, de Dante - busca para as obras que cita, sem cessar, uma função comum, por ele resumida da seguinte forma: "Uma e outra, (...) como obras de linguagem posta em ação - fontes da palavra ativa, atuante - permitem-nos discernir o real para além do dado imediato, empírico" (NUNES, 2005, p. 293). Afinal, como Benedito dirá mais à frente em seu texto, "a Filosofia não é uma ciência real, mas virtual, que se extrema nas concepções metafísicas do Universo" (NUNES, 2005, p. 297). É no espaço lógico ou poético de suas linguagens que o mundo se constitui e se resolve, e isso sob condições que não podem ser puramente fáticas, mas - para falar como o Wittgenstein do Tractatus - transcendentais, sendo o mundo, nesse sentido, uma imagem refletida (Spiegelbild) de um "sujeito metafísico" (WITTGENSTEIN, 1994, 5.641, p. 247). Um sujeito que determina não o que "é", mas o "como" as coisas são; ele "é anterior ao como, não é anterior ao quê [ist vor dem Wie, nicht vor dem Was]" (WITTGENSTEIN, 1994, 5.552, p. 241).

Essa função comum à filosofia e à literatura - seria melhor dizer à poética -, é, como se vê, derivada de um telos meta ta physika, reconhecido em ambas. Ambas são, nas palavras de Benedito Nunes, "tipos de compreensão" do mundo "por nós criadas como se fossem obras de arte". Em termos contemporâneos: estão, as duas, identificadas, também, por um constante e radical estado de crise. Afinal, não é apenas a filosofia, sobretudo em sua imagem enquanto uma modalidade de saber metafísico, que se vê confrontada com a positividade científica do real. Essa é uma questão que, segundo Adorno, emerge de nosso esforço em compreender a natureza da arte e de tudo a que atribuímos valor estético, pois sua pretensão à "liberdade absoluta", "que é sempre a liberdade num domínio particular", entra "em contradição com um estado perene de não-liberdade no todo". Por isso, à "realidade" da arte está agregada uma sus- 
peita quanto a sua justificação, já que falharam, diz Adorno, "todas as tentativas" de indicar o seu lugar "através de uma função social" (ADORNO, 1988, p. 11), objetiva. E assim como ainda se pergunta e perguntará, como Heidegger, "Qu'est-ce que la philosophie?" e/ou "Que é metafísica", Adorno aponta para "a incerteza do 'para quê' estético":

Não se sabe se a arte pode ainda ser possível; se ela após a sua completa emancipação, não eliminou e perdeu os seus pressupostos. A questão brota a partir do que ela foi outrora. As obras de arte destacam-se do mundo empírico e suscitam um outro com uma essência própria, oposto ao primeiro como se ele fosse igualmente uma realidade (ADORNO, 1988, p. 11-12).

Benedito e Adorno estão, desde há muito, bem acompanhados, tanto no que diz respeito à filosofia quanto no que se refere à arte. A maioria de nós, creio, sabe do valor superior dado por Aristóteles à poética, comparada, em seu modo próprio de narrar, com o que chamaríamos hoje de descrição objetiva dos fatos pela epistéme denominada história. Lemos na Poética, capítulo IX, que, manifestamente [phaneròn], "não é ofício do poeta [poietou] narrar o que aconteceu, e sim o que poderia acontecer, quer dizer: o que é possível segundo a verossimilhança e a necessidade" (ARISTÓTELES, Poética, 1451a 36). Aristóteles deriva a superioridade da poética - assim como o faz quando do estabelecimento da superioridade da sabedoria filosófica, na Metafísica - daquela "liberdade absoluta", como diz Adorno, com que se apresentam frente a empeiría, afinal, "a linha de demarcação entre a arte e empiria não deve ser ofuscada de nenhum modo" (ADORNO, 1988, p. 15). E como lemos na Poética: "a poesia é algo de mais filosófico e mais sério do que a história, pois refere aquela principalmente o universal (tà katholou), e esta o particular (kath'ekaston)" (ARISTÓTELES, Poética, 1451b).

Em O tempo na narrativa, de 1988, os vários elementos em que a verossimilhança e a necessidade não só se aliam como vinculam fortemente o mundo metafísico e ficcional são muitíssimo evidentes. E desde as primeiras linhas, Benedito Nunes, ancorado em Thomas Mann, assinala a exigência autoimposta pelo romancista, que para bem ordenar sua narrativa quer entender como distribuí-la no tempo. Ora, logo o tempo, que no Timeu, de Platão, não se reduz meramente à imagem móvel - e indireta - da eternidade; e que Aristóteles, no livro IV de sua Física, distingue por conter uma aporia, já que ele pode ser abordado tanto como infinito quanto por meio de períodos artificialmente compostos, ou kaì ho àpeiros kaì ho aeì lambanòmenos chrónos (ARISTÓTELES, Física, 218a). Uma vez que o tempo é condição incontornável da narrativa, para Thomas Mann a questão é saber: "Pode-se narrar o tempo, o próprio tempo, o tempo como tal e em si [diese selbst, als solche]" (MANN, 1980, p. 601). Isso cobra que saibamos o que "é" o tempo, e o ficcionista se converte em filósofo, o problema da narrativa passa a ser ontológico.

Como podemos notar, o que o Benedito faz ao falar de seu modo crítico de filosofar - que é, como ele mesmo o admite, kantianamente regulado, sem jamais ser kantianamente determinado -, é, por ser crítico, radicalmente antidogmático. E esse antidogmatismo na filosofia - ao qual Kant fornece a ideia reguladora -, para quem foi minimamente alfabetizado nele, como o próprio Benedito, é o signo da recusa em reduzir a filosofia à condição de mera ciência e uma, muitíssimo consequente, reaproximação, via Critica do Juízo, do eros que atrai, indistintamente, o sophós e o poietés. Esse antidogmatismo oriundo da visão crítica é uma espécie de antídoto, um pharmachon, à esquizofrenia que nós, lá no começo da história da filosofia, atribuímos, justa ou injustamente, a Platão, que já era, então, apesar de tudo que dizemos dele à distância, poietés kaì sophós, poeta e filósofo. Aliás, e isso é muito importante aqui: primeiro, poeta... depois, filósofo.

Talvez seja exatamente por isso que Benedito Nunes escreve, em Hermenêutica e Poesia, subtítulo: "O pensamento poético" - o que desfaz a esquizofrenia a que me referia -, o seguinte: 
"Desde o seu nascimento, a filosofia nunca foi indiferente à poesia" (NUNES, 1999, p. 13). Em seu memorial, ao fazer um balanço da repercussão, entre os contemporâneos de Kant, da estética como domínio filosófico autônomo, era inevitável apontar, entre os Românticos, para "a coincidência da Filosofia com a Poesia como equivalência entre gêneros" (NUNES, 2005, p. 294).

Essa proximidade entre filosofia e poesia, que nós atualizamos como filosofia e estética - pelo que nos indicam os poucos pontos de que tratamos na abordagem dada ao tema -, mais que nos sugere, ainda que tendamos a acentuar supostas diferenças entre Aristóteles e Platão, de um lado, e Kant e o Romantismo, por outro, recobrindo isso tudo, a óbvia regularidade do vínculo congênito entre o que nós, certamente, continuaremos a chamar de dois domínios distintos. Mas, essa congeneridade só pode ser desfeita - e é isso que o Professor Benedito evita, creio, quase instintivamente - com o risco para os dois gêneros, pares siameses que são, até no que ambos têm de problemático.

Por ser um pensador cauteloso, Benedito Nunes, aparentemente, aceita, como ele mesmo escreve em Hermenêutica e Poesia, que é na filosofia moderna que "prosperou, depois de Kant, o interesse filosófico pela poesia e pela arte" (NUNES, 1999, p. 13). Acontece que ele mesmo nunca respeitou nem a datação, nem a limitação na escolha das obras e dos autores no trânsito que tinha entre eles e elas. A bibliografia que produziu é a prova disso. $E$ a "passagem para o poético", que dá nome ao seu livro mais conhecido, é um tema cuja abordagem remete à ontologia e a filosofia contemporânea, por meio de Heidegger. Mas o apoio teórico, que cimenta toda a análise vem da Metafísica, de Aristóteles, obra que nos proporcionou a primeira história filosófica, portanto, crítica, da filosofia.

E creio ser possível dizer que, para a forma como pensa Benedito Nunes, fazer uma história "crítica" da filosofia não diferiria em quase nada do tratamento dado por Aristóteles ao assunto no Livro Alfa de sua obra mais importante. É que assim como, tanto em seu memorial quanto em Passagem para o poético ou em Hermenêutica e Poesia - só para ficar nessas referências -, o Professor Benedito arrola, indistintamente, Homero, Hesíodo, Platão, Aristóteles, Lucrécio, Shakespeare, Santayana, Schlegel, Novalis, Baudelaire, Goethe, Carlos Drummond, Dante, Kant, Espinosa, Sartre, Heidegger, Merleau-Ponty, etc., Aristóteles, na busca da epistéme a que chama de sophia, não tem o menor pudor em colocar na lista daqueles que buscavam conhecer as primeiras causas e os primeiros princípios - e a quem chamou, expressamente, de primeiros filósofos [ton próton philosophesánton] -, os philómythos, ou seja, os mitólogos, que nada mais eram do que poietés, poetas. Diz o texto de Aristóteles: "o que ama os mitos [philómythos] é, em certo sentido, philósophos [o que ama a sabedoria]" (ARISTÓTELES, Metafísica, 982 b 17).

É certo que a imagem do professor Benedito, talvez até aquela em que ele se via refletido, é a de um pensador "contemporâneo". Mas, talvez isso se deva a um desses equívocos da linguagem - e próprios de sua função de idola, como dizia Francis Bacon. Creio ser possível dizer que Benedito Nunes, relativamente às fontes seguras de que lançava mão frequentemente, era um "moderno". Bastaria lembrar em quantas ocasiões, ao tratar da filosofia e da poesia, ele nos aponta que "tudo começa com Kant", quando se trata do reconhecimento mais recente do valor filosófico das questões de ordem estética. Levando em conta a metafísica, apenas, Nietzsche já nos tinha dito que "tudo começa com Platão". Conhecedor que era do lon, é o próprio Benedito Nunes quem resolve, creio eu, a questão - ou, um dos eternos mal-entendidos que levam tantos "filósofos" a falar contra a própria filosofia em nome da poesia -, ao escolher a epígrafe de seu memorial à Academia. Na trilha de Novalis, quando este escreve: "O poeta conclui, assim que começa o traço" (NOVALIS, 2001, p. 121), Benedito Nunes concentra sua "solução" em uma frase de Hermann Bloch, extraída de $A$ morte de Virgílio, em que se lê: "Onde Platão acertou, a Filosofia converteu-se em Poesia". 
Pois bem: é correto quando Benedito Nunes toma Kant como ponto de partida, principalmente, é claro, identificando o contexto desse começo ao texto da Crítica do Juízo, que diferente de suas duas primeiras grandes obras, não visa oferecer um fundamento doutrinal à filosofia e sim meramente enciclopédico. Daí poder-se dizer que teoria do juízo de reflexão estético faz parte da perspectiva crítica, mas sem nenhuma vocação dogmática. Nas palavras de Kant: "Uma introdução enciclopédica [...] não pressupõe, eventualmente, uma doutrina, uma doutrina aparentada e preparatória para a doutrina que se enuncia como nova, mas a Ideia de um sistema, que somente com aquela se torna completo" (KANT, 1995, p. 80).

O que ocorreu depois da terceira das críticas - e que nos ajuda a entender o espírito da atividade crítico-filosófica de Benedito Nunes - foi o que nós poderíamos, em princípio, chamar de mudança do centro de gravidade e uma aceleração inesperada do giro copernicano no interior do conceito "moderno" de filosofia, antes fortemente marcado e condicionado pela influência da física de Newton. Com a ajuda de Kant, ainda na primeira crítica, no entanto, deixando o pudor de lado, creio que poderíamos afirmar que o que ocorre de fato é a recuperação do autêntico e originário conceito de filosofia, reconhecível não só nas palavras grafadas e legíveis, até hoje, de Platão e Aristóteles, mas naquilo que o pensamento de ambos tem de verdadeiramente metafísico. É uma verdade que pertence tanto à letra quanto ao espírito de suas obras.

Por isso, o pensamento contemporâneo do Professor Benedito Nunes, que escreveu, aliás, uma obra intitulada Filosofia contemporânea, só é contemporâneo, filosoficamente falando, no sentido pobre em que fazemos uso dessa palavra. Um uso contingente e inessencial, já que esse registro momentâneo, histórico, limitado artificialmente no tempo, é um registro empírico que, como vimos, pouco importa à filosofia e ao modo como Benedito Nunes mobiliza todo o repertório fornecido pela história da cultura. Mas, como ele mesmo nos mostra ao com-pôr Spinoza e Dante, nem a literatura, mesmo aquela praticada com pretensos fins realistas, como a de João Cabral de Melo Neto, é uma mera expressão linguística de fatos empíricos.

Na contemporaneidade, Benedito Nunes só fez filosofia, e também - e justamente por isso anulando as diferenças -, só fez crítica literária em alto nível, por se ter posto num plano extemporâneo. O ser e o tempo, o problema da determinação ontológica do mundo na tensão entre tempo e eternidade (chronos e aion), e a necessidade de reconhecer em chronos a figuração do que sempre é e nunca muda, porém somente na condição, inevitável, do movimento, essa diferença entre tempo puro e tempo empírico que, como nos mostra Newton, no mesmo instante, atrela um ao outro dando-lhes um sentido, ainda que vago, é o que torna contemporâneo o pensamento elevado. E é isso que ocorre no "caso" do Professor Benedito Nunes. Nele vemos "um" caso de pensador contemporâneo porque nele se atualiza o que sempre é, e o que sempre é, justamente, não é da ordem empírica. É, isso sim, meta ta physika. A filosofia autêntica é, invariavelmente - metafisicamente, portanto - contemporânea, como dizemos que as obras de arte, e de filosofia, aquelas que realmente merecem esse nome, são obras eternas.

\section{Do acabamento estético da filosofia moderna e contemporânea}

A partir de agora, meu objetivo é mostrar como Benedito Nunes, ao reunir em seus escritos filosofia e crítica literária (romance e poesia), alinha-se a uma tradição do pensamento alemão em que a "passagem" para a reflexão estética se mostra o início (aqui estou pensando em Kant) e o fim (e aqui estou pensando em Schelling e Schopenhauer) de toda ação reflexiva. Início porque, apesar de Baumgarten, é com a Crítica do Juízo que temos a determinação aca- 
bada das condições de elaboração de uma estética filosófica autônoma; e o fim, no sentido de que esse acabamento estético é entendido, pelo idealismo alemão, sobretudo por Schelling, Hölderlin e, depois, Schopenhauer, como o acabamento da própria filosofia. Os amigos Hegel, Hölderlin e Schelling, aparentemente, se situavam na mesma ordem de consideração kantiana, no que tange à valorização filosófica da estética. É o que podemos deduzir do famoso fragmento reconhecido como o mais antigo programa sistemático do idealismo alemão, segundo o qual "a Ideia que unifica tudo" é

a Ideia de beleza, tomada a palavra em seu sentido superior, platônico. Pois estou convicto de que o ato supremo da Razão, aquele em que ela engloba todas as Ideias, é um ato estético, e de que verdade e bondade só estão irmanadas na beleza. O filósofo tem de possuir tanta força estética quanto o poeta. (SCHELLING, 1984, p. 42).

Ninguém estranharia se este texto fosse parte de um manifesto romântico, como uma declaração de princípios que desloca a imagem do filósofo, indo daquelas tradicionais, em que ora aparecia o cientista, ora aparecia o moralista, para a imagem do poeta, cujo arquétipo é o gênio de Homero. E o Romantismo, ainda que possa ser considerado um caso especial e sui generis de filosofia, como pretende Nicolai Hartmann (HATTMANN, 1983, p. 189-272), é a encarnação plena desse novo centro emanador do pensamento, que é o juízo-de-reflexão estético, uma modalidade de pensamento que não se detém ou não se autolimita e fixa em conceitos acabados. Há um fragmento de Novalis em que essa liberdade infinita da reflexão é exaltada:

Onde o genuíno pendor ao refletir, não meramente ao pensar deste ou daquele pensamento, é dominante, aí há também progressividade. Muitíssimos doutos não possuem esse pendor. Aprenderam a concluir e inferir, como um sapateiro a confecção de sapatos, sem jamais caírem na ideia de, ou esforçarem-se para, encontrar o fundamento dos pensamentos. Contudo, a salvação não está em nenhum outro caminho. Em muitos esse pendor dura apenas por um tempo. Cresce e diminui, muito frequentemente com os anos, frequentemente com a descoberta de um sistema, que só procuravam para, a seguir, ficar dispensados da fadiga de reflexão. (NOVALIS, 2001, p. 62).

Por isso, se entendemos corretamente o sentido da unidade que a terceira crítica dá ao sistema kantiano, é possível afirmar que a nova modalidade de reflexão aí exposta, a reflexão estética, pode ser considerada como a autêntica base afirmativa do pensamento, e como tal, o fundamento originário, mesmo para suas formas mais rígidas, doutrinais e abstratas. Certamente, a figura intelectual de Benedito Nunes, como de outros pensadores contemporâneos, é marcada por esse pendor reflexivo de que fala Novalis. Por isso, pode ser interessante e instrutivo, estabelecer um paralelo entre a produção filosófico-literária de Benedito Nunes e o fenômeno, também filosófico-literário, ocorrido na Alemanha em fins do século de XVIII e início do século XIX, e que recebeu o nome, prenhe de ambiguidades, dada sua recepção multívoca, de Romantismo.

Para diminuir os rodeios e evitar alguma infidelidade, farei uso de um texto do próprio Benedito Nunes, derivado do material utilizado em uma de suas aulas sobre "Hermenêutica e poesia", subtítulo: "o pensamento poético", de um curso por ele ministrado na UFMG, em 1994. A aula em questão intitula-se, justamente, "Romantismo e idealismo germânico". Trata-se de um texto muito adequado já que a ideia é associar a redescoberta da importância da produtividade poética do pensamento em fins do século XVIII e o rigor conceitual que levou, para espanto geral, à valorização das formas livres de ajuizamento, consideradas aqui como anteriores aos esforços tradicionais em determinar critérios unívocos (quer dizer: conceituais) de ordenação do nosso conhecimento e dos nossos valores morais.

Em fins do Século XVIII, com uma espécie de arqueologia transcendental, Kant tentou mostrar como as funções dos nossos juízos, reconhecidas desde Aristóteles por meio de três 
padrões de pensamento, vão se alargando, na medida em que passamos das reflexões teóricas às reflexões morais e, dessas últimas, aos nossos juízos sobre o gosto. Esse alargamento do pensamento é descrito como um recuo gradual do uso restritivo de conceitos, até culminar em uma espécie de "epoché" dos mesmos, liberando nossa imaginação de toda regra determinante no ato de pensar, ou seja, na própria reflexão. Nisso, Kant reúne dois coisas aparentemente inconciliáveis, afinal, o resultado do programa crítico é justamente essa associação entre rigor analítico e liberdade, que, no pensamento, está associado à produtividade imaginativa. E é exatamente isso que gostaríamos de fazer notar nos trabalhos que nos deixou o Professor Benedito Nunes. É que apesar da independência que ele se outorgou com a escolha do estilo ensaístico para seus trabalhos - o que, aliás, tanto interessava a figuras ilustres, como Goethe -, quando me refiro, no título, ao que é bene dictum, estou pensando no cuidado conceitual que, como diria o Kant da terceira crítica, embora não domine a expressividade do pensamento, serve-lhe de referência, não virando nunca as costas, na criação compositiva, à verdade. Talvez não seja uma blasfêmia falarmos aqui como Benedito Nunes ao analisar as ideias contidas em $A$ educação pela pedra, de João Cabral de Melo Neto, em um análogo do que aí se denomina "A máquina do poema" (NUNES, 2009, p. 257-267).

De todo modo, o que me interessa explorar na obra filosófico-literária de Benedito Nunes é o reconhecimento, nela, de uma tendência que, independentemente de seus descaminhos (que são muitos), mudou, em grande medida, os rumos da filosofia, uma vez que tirou seu centro de gravidade das formas mais rigidamente controladas do pensamento, quais sejam, a ciência e a moral. A filosofia imediatamente pós-kantiana, de certo modo, deixou de ser, predominantemente, uma epistemologia, ou pelo menos não poderia mais ser reduzida a ela, e o filósofo não era mais confundido, diretamente, com o moralista, embora, como nos diz Schiller, os princípios éticos que a filosofia desvenda pelo kantismo sejam "antigas exigências da razão comum", e que "mereceram sempre o consenso entre os homens" (SCHILLER, 1995, p. 24). Mas, como lemos, também, nas cartas sobre $A$ educação estética do homem, o enorme esforço do entendimento para pensar abstratamente exige uma limitação do espírito e do mundo por meio dele representado. E libertar o espírito, diz-nos Schiller, é tirar "as severas algemas da lógica", o que propicia o "livre andamento da força poética" do pensamento (SCHILLER, 1995, p. 44). Fiel às consequências que podemos tirar da terceira crítica, Schiller escreve:

o predomínio da faculdade analítica rouba necessariamente a força e o fogo à fantasia, assim como a esfera mais limitada de objetos diminui-Ihe a riqueza. Por isso, o pensamento abstrato tem, frequentemente, um coração frio, pois desmembra as impressões que só como um todo comovem a alma. (SCHILLER, 1995, p. 42).

Há uma passagem em Hermenêutica e poesia, em que Benedito Nunes diz:

Na filosofia moderna, prosperou, depois de Kant, o interesse pela poesia e pela arte. Interesse cognoscitivo pela poesia como meio de conhecimento, que o neokantismo aprofundou (particularmente Cassirer), quando o Romantismo já concebera a associação entre o filosófico e o poético. (NUNES, 1999, p. 13).

O que eu gostaria de acentuar nessa passagem é como, por compreender perfeitamente o que ocorre nesse movimento iniciado com a última crítica, Benedito Nunes aponta para o fato de o interesse pela poesia ser de natureza cognoscitiva, ou seja, integrada ao escopo epistemológico da filosofia transcendental, apesar de o resultado da análise crítica do gosto redefinir a relação que temos com o objeto estético, liberando-o, como diz Schiller, das "severas algemas da lógica". Benedito Nunes não antecipa as coisas, não se precipita, por mais econômico que seja na referência a Kant. A especificidade do objeto estético, assim como do juízo de gosto é 
determinada, ou seja, rigorosamente delimitada, a partir da uma investigação tão consistente e exigente quanto o fora no caso dos princípios objetivos da ciência e da moral, nas duas primeiras críticas. É que a base formal, ou seja, a estrutura primária de toda e qualquer forma de pensamento é, e tem de ser, a mesma, servindo tanto à analítica transcendental quanto à analítica do belo. A não saber para aqueles que queiram abrir mão da reflexão. E isso é, certamente, reconhecido por Benedito Nunes, ao afirmar que é graças a Kant como referência no redirecionamento da filosofia moderna que não se fala de pensamento " $e$ " poesia, mas de "pensamento poético", cuja forma lógica é o juízo de reflexão ou estético.

A compreensão dessa base formal, ainda que livre, sobre a qual se estrutura o juízo de gosto é resumida com precisão em uma passagem de Hermenêutica e poesia, nos seguintes termos: "Kant está retirando a Estética" de "dentro da problemática relativa" ao "conhecimento teórico e suas relações com o conhecimento ético, moral ou prático". E continua:

\begin{abstract}
Mas é no próprio círculo da crítica e, portanto, no âmbito da possibilidade de estabelecer certas espécies de juízo, que Kant coloca o Belo e também as Belas Artes. Dizer que ele fundamentará a Estética significa então dizer que fundamentará o Belo como objeto de juízo de gosto estético. Gosto não é apenas um sentimento, como pensavam os críticos ingleses, mas é também a especificidade de um juízo, o juízo de gosto, e é essa especificidade que constitui a matéria da experiência estética" (NUNES, 1999, p. 33).
\end{abstract}

E há algo mais, segundo Benedito Nunes, pois a valorização da imaginação produtiva, ou seja, poética - frente à imaginação empírica ou meramente reprodutiva -, a cujas representações Kant chama de "ideias estéticas", é o que nos permite pensar além da objetivação do sensível, ou seja, além da via da lógica transcendental, que é puramente abstrata. O que a imaginação representa aqui, nas "ideias estéticas", não pode ser cotejado com nenhum conceito. Por isso, "a beleza na arte, se torna símbolo, enquanto representação indireta de possíveis conceitos". E essa saída do empírico sustentada na representação do Belo é o que faz, diz Benedito, da "Terceira crítica, na sua primeira parte", "'o primeiro manifesto romântico"' (NUNES, 1999, p. 35). Segundo Benedito, nessa página: "O poeta romântico vai passar do típico, do genérico do classicismo para o característico, para a singularidade individual, por meio do gênio, considerado como faculdade produtiva".

Para Benedito Nunes, o objetivo do Romantismo, como o dele próprio, era "encontrar o elemento comum do que é artístico", e esse elemento comum tem uma designação que muitos haverão de estranhar, pela falta de rigor com que "acham" que seja a emergência da estética, na medida em que levam em conta, apenas, o fato desta, a estética, ser posta ou encontrar-se fora dos limites da epistemologia e da moral. E não é esse o caso, pois então a descoberta em questão seria cega, às apalpadelas e sem critério firme que a guiasse e garantisse. É que esse elemento buscado remete a um conceito tradicionalíssimo e, para muitos, simplesmente dogmático, pois tal elemento é "a reflexão da consciência de si, autodelimitando-se numa forma" (NUNES, 1999, p. 39). Portanto, o foco é a atividade do Eu, tida, nesse caso, não apenas como atividade originária, mas, também, infinita. Isso exige, de quem deseja conhecer verdadeiramente o Romantismo alemão, um mergulho na obra de Kant e Fichte, coisas que poucos, principalmente na filosofia mais recente, são ou foram capazes. Uma exceção importante é citada por Benedito Nunes. Trata-se de Walter Benjamin, que escreveu uma obra, muito mal compreendida, mesmo entre especialistas, chamada $O$ conceito de crítica de arte no romantismo alemão, e que começa suas análises afirmando: "O pensamento que reflete sobre si mesmo na autoconsciência é o fato fundamental do qual partem as considerações gnosiológicas de Friedrich Schlegel e, em boa medida, também as de Novalis" (BENJAMIN, 1988, p. 41). Não é à toa que essa é uma obra incompreensível àqueles que fogem da filosofia rigorosa, coisa de que Benedito 
Nunes nunca temeu ou se esquivou. Muito pelo contrário, afinal era, como tenho dito, a preocupação com o rigor que dava à sua crítica literária o respeito e a profundidade que justificam sua reputação.

O ponto aqui é entender o que é uma atividade não só reflexiva, mas, também, criadora e poética para os românticos. E é, diz Benedito, "nessa mesma reflexividade que a filosofia se fundamenta. Assim, arte e filosofia procederiam de um elemento reflexivo comum, como nos mostra o conhecido trabalho de Walter Benjamin" (NUNES, 1999, p. 39). E a reflexividade, tomada como o ater-se da consciência em si mesma e o considerar a si mesma, "é o elemento gerador da intuição intelectual" buscada pelos românticos, embora rejeitada por Kant, que não vê aí um valor teórico. Mas, o que interessa perceber no conceito de crítica de arte romântica, segundo Benjamin, quando da delimitação de seu problema, é o fato de que:

Uma determinação do conceito de crítica de arte seria impensável sem alguns pressupostos gnosiológicos, como também sem alguns pressupostos estéticos; não só porque estes últimos implicam os primeiros, senão que, sobretudo, porque a crítica contém um momento cognoscitivo (...). Desse modo, também a determinação romântica do conceito de crítica de arte foi construída inteiramente sobre premissas gnosiológicas. (BENJAMIN, 1988, p. 29-30).

Portanto, não há uma reflexão acerca da arte, e, no caso do Professor Benedito Nunes, acerca da poesia e da literatura em geral, sem uma base sólida. E essa base é invariável, quando se quer pensar filosoficamente e não de modo meramente retórico e envolvente. Se o filósofo, assim como o crítico, no sentido de que deles falam Kant e Benjamim, dominam sua própria atividade, isso se deve ao fato de manterem, nesse espaço mais leve e menos repressivo logicamente a que damos o nome de reflexão estética ou mesmo de pensamento poético, o cuidado mínimo, que é exatamente o rigor que nos leva a expressar - ainda mais em público e para o público - o que não apenas pode, mas o que deve ser bene dictum, seja ele Nunes ou tenha ele outro sobrenome.

\section{Referências}

ARISTÓTELES. Poética. São Paulo: Abril Cultural, 1984.

ARISTÓTELES. Poetik (Griechisch/Deutsch). Stuttgart: Philipp Reclam, 1991.

BENJAMIN, W. El concepto de crítica de arte em el romanticismo alemán. Barcelona: Ediciones Península, 1988.

HATTMANN, N. A filosofia do idealismo alemão. Lisboa: Fundação Calouste Gulbenkian, 1983.

KANT, I. Duas introduções à Crítica do Juízo. São Paulo: Iluminuras, 1995.

MANN, T. A montanha mágica. Rio de Janeiro: Nova Fronteira, 1980.

MANN, T. Der Zauberberg. Frankfurt: Fischer Verlag, 1997.

NOVALIS. Pólen. São Paulo: Iluminuras, 2001.

NUNES, B. Hermenêutica e poesia - O pensamento poético. Belo Horizonte: Humanitas, 1999.

NUNES, B. Meu caminho na crítica. Estudos Avançados. São Paulo, v. 19, n. 55, p. 289-305, 2005.

NUNES, B. O dorso do tigre. São Paulo: Ed. 34, 2009.

NUNES, B. O tempo na narrativa. São Paulo: Editora Ática, 1988. 
SCHELLING, F. W. J. Obras escolhidas. São Paulo: Abril Cultural, 1984.

SCHILLER, F. A educação estética do homem. São Paulo: Iluminuras, 1995.

\section{Sobre o autor}

\section{Pedro Paulo da Costa Coroa}

Doutor em Filosofia pela Universidade de São Paulo (USP). Pós-Doutorado pela Martin-Luther-Universität Halle-Wittenberg. Docente da FAFIL/PPGFIL da UFPA, com pesquisas em Ética e Estética.

Recebido em: 07.08.2021.

Aprovado em: 09.09.2021.
Received: 07.08.2021.

Approved: 09.09.2021. 